\title{
Research on the heat collecting efficiency of flat-plate collector and
}

evacuated tube collector

\author{
Zhihua Zhou ${ }^{1, a}$, Junwei Liu ${ }^{1, b}$, Xin Huang ${ }^{2, c}$ \\ ${ }^{1}$ Tianjin Key Laboratory of Indoor Air Environmental Quality Control, Key Laboratory of Efficient Utilization of \\ Low and Medium Grade Energy, School of Environmental Science and Engineering, Tianjin University, \\ Tianjin, China; \\ 2 Tianjin Fuli Real Estate Development Co., Ltd, Tianjin, China. \\ a zhuazhou@163.com \\ bjwliu628@163.com \\ cxhuang827@163.com
}

\begin{abstract}
Key words: solar hot water system, evacuated tube collector, flat-plate collector, heat collecting efficiency
Abstract. As the most mature kind of solar heat utilization technology, solar hot water system has been widely used and popularized. In this paper, the evacuated tube collector and the flat-plate collector are used as the research object. The two kinds of collector are most used, while the proportion of use at home and abroad is quite different. The heat collecting efficiency of the two kinds of heat collector is compared by the simulation method. The results show that the annual average heat efficiency of the evacuated tube solar water heating system is $42.9 \%$, which is lower than that of the flat-plate solar hot water hot water system by $47.1 \%$. In the whole year, the heat efficiency of the two sets was the largest in August, and the lowest in December. The reason is that the outdoor temperature has great influence on the heat collecting efficiency of the flat-plate solar collector, and the lower the ambient temperature, the lower the heat collecting efficiency. The evacuated tube collector has better thermal insulation performance and is less affected by the environment.
\end{abstract}

\section{Introduction}

The proportion of total energy consumption in total energy consumption in China has risen from $10 \%$ in the late 70 s to about $28 \%$, and this proportion will continue to rise. In order to cope with the increasingly severe energy and environmental problems, the application of renewable energy is becoming more and more important. As an important kind of renewable energy, solar energy has been developed rapidly and widely used in recent years, especially the application of solar hot water in building.

At present, the most used heat collector in the solar hot water system is the flat-plate solar collector and the evacuated tube solar collector. The flat-plate solar collector has the advantages of high thermal efficiency at low temperature, stable and reliable long-term operation, good pressure performance and easy to combine with building. The shortcoming is the heat loss that is easily produced by the heat collector through conduction, convection and radiation. The evacuated tube solar collector has the advantages of small heat loss coefficient and good antifreeze performance, but it is easy to burst due to high temperature or high pressure. The evacuated tube collector occupies a large proportion in China, although the flat-plate collector has increased steadily in recent two years, it accounts for only about $10 \%$ to $15 \%$ of the market share. But in the European and American markets, this is the opposite, the market share of the flat-plate solar collector is about $90 \%$, and the evacuated tube share is less than $10 \%$.

Research shows that, due to the flat-plate solar collector (FPSCs) in high thermal efficiency at low temperature, so its operating temperature is generally $20-80^{\circ} \mathrm{C}$ [1], while the thermal efficiency of evacuated tube solar collector (ETSCs) can remain high at high temperature, the operating temperature range is 50-200 ${ }^{\circ} \mathrm{C}$ [2]. Many scholars have studied the two kinds of collectors. Budihardjo I et al.modeled the solar 
hot water system of the evacuated tube collector using the transient analog software TRNSYS, the results show that for the $135 \mathrm{~L}$ water tank system, it can save $45 \%$ energy throughout the year [3]. Zishuai Sun et al. established the mathematical model of the double glass cover plate solar collector based on the finite volume method and analyzed the influence of environmental temperature, inlet water temperature, solar radiation intensity and the lower glass plate position on the thermal performance of the collector, and compared with single glass cover plate collector. The results show that when the environment temperature is below $18^{\circ} \mathrm{C}$, double glass cover plate collector is more advantageous. When the environment temperature is $-10^{\circ} \mathrm{C}$, the instantaneous efficiency of double glass cover plate collector is $26 \%$ higher than ordinary flat collector; When inlet water temperature is $50{ }^{\circ} \mathrm{C}$, the instantaneous efficiency of double glass cover plate collector is $27 \%$ higher than single-layer glass flat plate collector; The instantaneous efficiency of the collector can reach up to $67.8 \%$ when the lower glazing plate is $18 \mathrm{~mm}$ above the absorber plate [4]. Ayompe et al. has carried on the comparative study about flat plate collector and a heat pipe evacuated tube collector, the results show that under the same conditions, the heat colleting efficiency of flat plate collector and heat pipe evacuated tube collector is $46.1 \%$ and $60.7 \%$ respectively, and the system efficiency is $37.9 \%$ and $50.3 \%$ respectively [5].

Since the evacuated tube type collector is more efficient than the flat-plate collector, why more flat-plate heat collectors abroad? The previous research is mainly based on the decentralized solar collector, which is the household independent collector. How is the collective heat collector application? In this paper, the collective heat collection system is taken as the research object. First, the accuracy of TRNSYS software modeling is verified by experiments. Then the collecting efficiency of two kinds of collectors is simulated and evaluated.

\section{Methods}

The object of this study is located in the north of China, Tianjin, which is 117.10 degrees in the East and 39.06 degrees in the north latitude. The solar energy is abundant, the annual sunshine hours are $2600-2800 \mathrm{~h} / \mathrm{a}$, the annual solar radiation is $5400-6700 \mathrm{MJ} / \mathrm{m}^{2}$ a, and the annual average outdoor temperature is $13^{\circ} \mathrm{C}$.

Research object. Two collective solar hot water systems are selected, the evacuated tube solar collector and the flat-plate solar collector are respectively used in the two systems.

The systems of evacuated tube solar collector. The daily water consumption of the project is $10 \mathrm{t}$, the design temperature of water supply is $60^{\circ} \mathrm{C}$, the design temperature of cold water is $15^{\circ} \mathrm{C}$, the collector area of collector is $150 \mathrm{~m}^{2}$, the auxiliary heat source is $120 \mathrm{~kW}$ electric heater.

The systems of flat-plate solar collector. The project is the domestic hot water system of a multi-storey residential building, the design of collective hot water system is 39 households, the highest daily water consumption quota is $120 \mathrm{~L} /$ household, the total water consumption is $4680 \mathrm{~L} /$ day. The hot water design temperature is $60^{\circ} \mathrm{C}$, the cold water design temperature is $15^{\circ} \mathrm{C}$ and the domestic hot water source is municipal tap water. The collector heat area is $150 \mathrm{~m}^{2}$.

Data simulation. Based on the meteorological data in Tianjin area, the Transient System Simulation Program (TRNSYS) simulation software is used to simulate the solar water heating system with two kinds of collectors respectively, and the operation characteristics of the system are analyzed. The components of TRNSYS software include: modeling platform Simulation Studio, modeling tool TRNBuild, program generation tool TRNExe and modification tool TRNEdit and optimization computing tool TRNOPT.

Simulation model of solar hot water system. A collective solar hot water system simulation model is set up in TRNSYS, as shown in Fig. 1. The modules include solar collector, water tank, circulating pump, meteorological parameters, control system, output module and so on. 


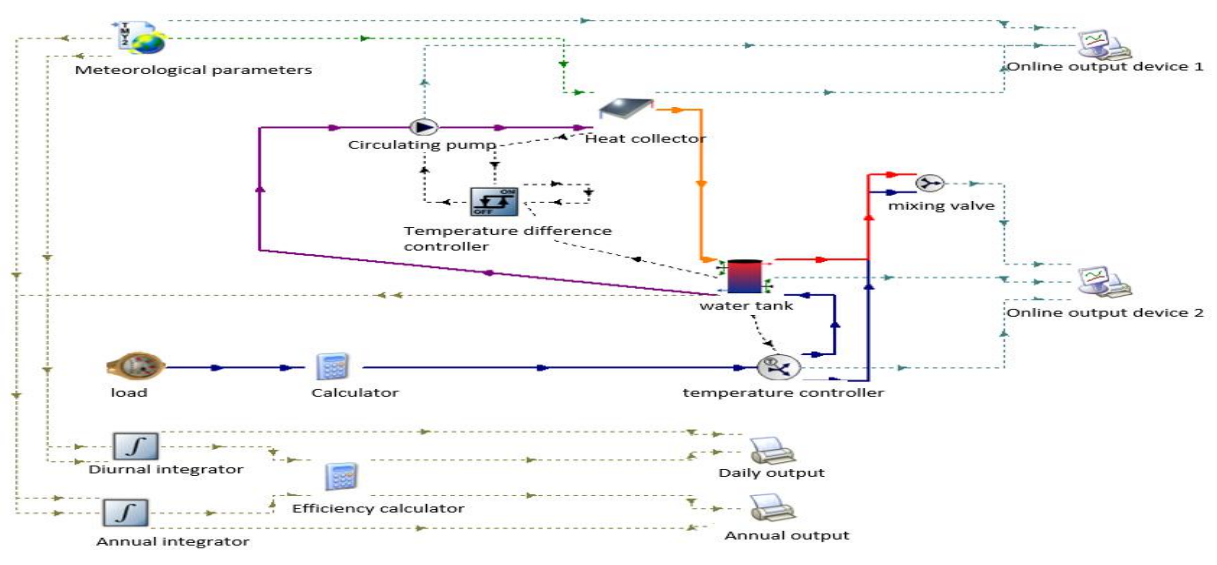

Fig. 1 collective solar water system simulation model

Model parameter settings: cold water temperature is $15^{\circ} \mathrm{C}$, the initial temperature of the water tank is $35^{\circ} \mathrm{C}$; the total area of the collector is $150 \mathrm{~m}^{2}$, the volume of the water tank is $8000 \mathrm{~L}$, the heat load of the user is $1778 \mathrm{MJ} /$ days. Set temperature control mode to control the thermal cycle system, the outlet temperature of heat exchanger is $T_{1}$, the average water temperature is $T_{2}$. When $T_{1}-T_{2}$ is larger than $7{ }^{\circ} \mathrm{C}$, the heat collecting circulating pump is opened, when the $\mathrm{T}_{1}-\mathrm{T}_{2}$ is less than or equal to $2^{\circ} \mathrm{C}$, the heat collecting circulating pump shut down, simulation step is set to $5 \mathrm{~min}$.

The parameter setting of the collector is as Eq. 1.

$$
\eta=a-b \frac{T_{i n}-T_{a}}{G}
$$

Where, $a$ means instantaneous efficiency intercept of collector, $b$ means instantaneous efficiency slope of collector, $T_{\text {in }}$ means inlet temperature of collector, $T_{\mathrm{a}}$ means ambient temperature, $\mathrm{G}$ means solar radiation intensity. For evacuated tube collector, $a$ is selected as 0.52 and $b$ is selected as 1.56; for flat-plate collector, $a$ is selected as 0.72 , and $b$ is selected as 4.58 .

Model verification. In order to simulate the accuracy of solar hot water system, the related parameters are tested during the operation of the above two systems including outdoor temperature, solar radiation intensity/solar radiation, inlet and outlet temperature of heat collector, circulating flow rate of collector, heat storage tank temperature, the water temperature of the user side, the water flow of the user side, water replenishment flow etc..

The test time is August 16, 2017, the weather data of the day is introduced into the TRNSYS to be simulated, and the inlet and outlet temperature of the collector side and the average temperature of the water tank are obtained. The accuracy of the model was verified by comparing the measured data of the evacuated tube solar water heating system with the TRNSYS simulation results on the same day.

The change of solar radiation intensity on the day of the test is shown in Fig. 2. The intensity of solar radiation is high and the highest point is over $800 \mathrm{~W} / \mathrm{m}^{2}$, and there's basically no cloudy situation. Only from 11:00 to 13:00, the solar radiation intensity decreases slightly due to cloud cover.

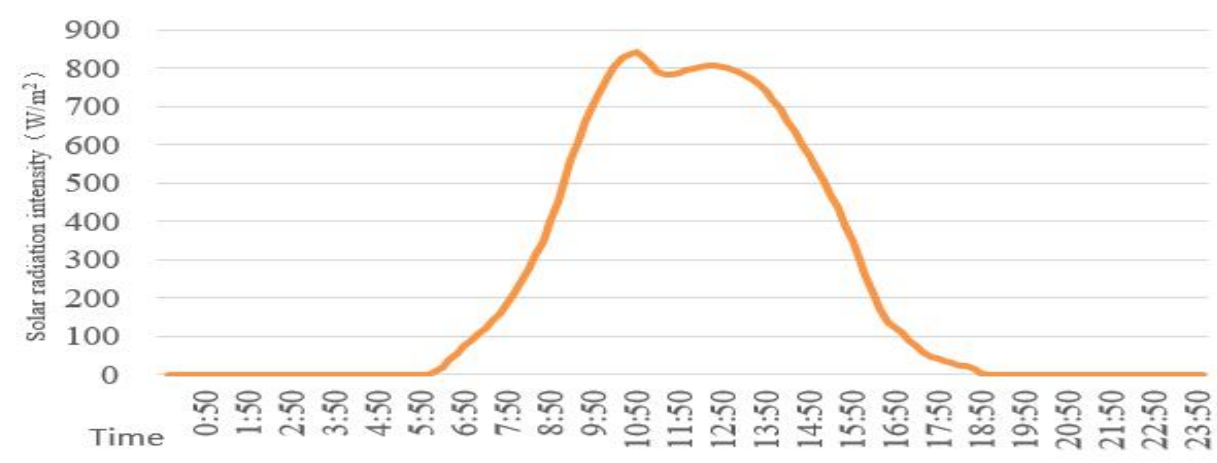

Fig. 2 the measured solar radiation intensity in August 16th 
The changing trend of the simulated and measured values of the inlet/outlet temperature of the collector and the temperature of the water tank is shown in Fig. 3.

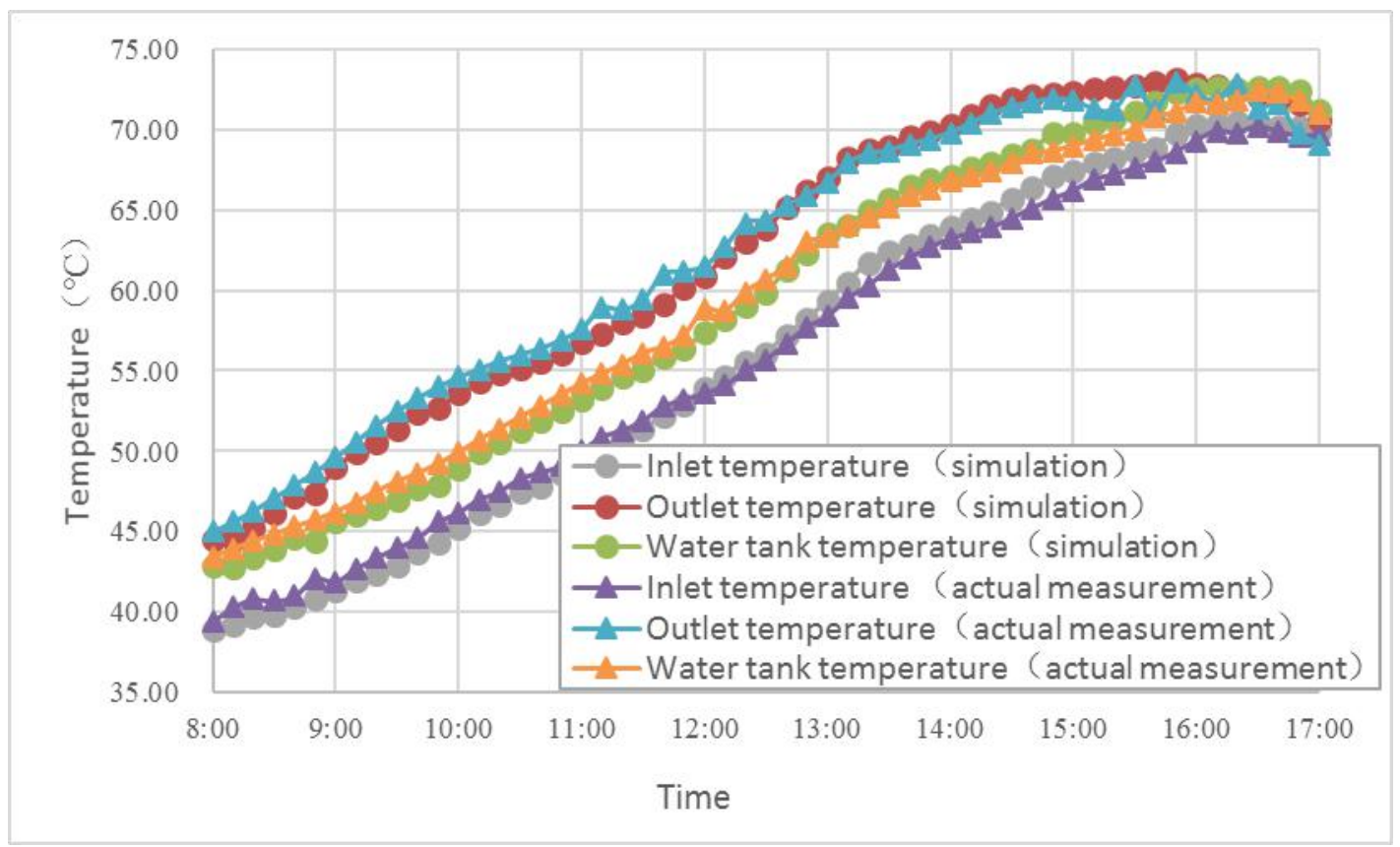

Fig. 3 TRNSYS model validation

From Fig. 3, it is known that the measured values of the inlet/outlet temperature of the collector and the temperature of the water tank are in good agreement with the simulated values, and the degree of anastomosis is better. In the 8:00 to 12:00, three measured temperatures are slightly higher than the simulated value, after 12:00, simulated values are slightly higher than the measured value, This is because only a single day of simulation has been simulated, but the real system is running continuously, the heat stored in the previous day will have a certain effect on the measured value. The relative error between the measured and simulated values of the inlet temperature of the collector is within $2.1 \%$. The relative error between the measured and simulated values of the outlet temperature of the collector is within $3.9 \%$, and the relative error between the measured and simulated values of the water tank is within $2.4 \%$. It shows that the model built and solved by TRNSYS is accurate.

\section{Result}

In order to obtain the annual operation effect of solar water hot water system, two kinds of systems are simulated for the whole year respectively. The results are shown in Table 1. 
Table 1 Simulated data statistics of the evacuated tube and flat-plate solar water heating system

\begin{tabular}{|c|c|c|c|c|c|}
\hline Month & $\begin{array}{c}\text { Monthly solar } \\
\text { radiation }\left(\mathrm{MJ} / \mathrm{m}^{2}\right)\end{array}$ & $\begin{array}{c}\text { Accumulated heat of the } \\
\text { evacuated tube } \\
\text { collector }\left(\mathrm{MJ} / \mathrm{m}^{2}\right)\end{array}$ & $\begin{array}{l}\text { Heat collecting efficiency of the } \\
\text { evacuated tub collector } \\
(\%)\end{array}$ & $\begin{array}{l}\text { Accumulated heat of the } \\
\text { flat-plate collector }\left(\mathrm{MJ} / \mathrm{m}^{2}\right)\end{array}$ & $\begin{array}{l}\text { Heat collecting efficiency } \\
\text { of the flat-plate collector } \\
\qquad(\%)\end{array}$ \\
\hline 1 & 284.7 & 117.3 & 41.2 & 120.9 & 42.5 \\
\hline 2 & 339.1 & 145.8 & 43 & 156.5 & 46.1 \\
\hline 3 & 510.7 & 220.5 & 43.2 & 245.4 & 48.0 \\
\hline 4 & 573.5 & 248.9 & 43.4 & 277.4 & 48.1 \\
\hline 5 & 694.9 & 298.7 & 43.9 & 330.7 & 48.2 \\
\hline 6 & 673.9 & 291.6 & 43.3 & 309.4 & 47.9 \\
\hline 7 & 581.8 & 256.0 & 43.7 & 277.4 & 47.7 \\
\hline 8 & 539.9 & 231.1 & 42.8 & 263.1 & 48.1 \\
\hline 9 & 493.9 & 220.5 & 44 & 238.3 & 47.6 \\
\hline 10 & 397.7 & 174.2 & 43.8 & 202.7 & 46.9 \\
\hline 11 & 276.3 & 113.8 & 41.2 & 128.0 & 46.3 \\
\hline 12 & 238.6 & 99.6 & 41.7 & 106.7 & 44.7 \\
\hline Aggregate/average & 5605 & 2418.1 & 42.9 & 2656.3 & 47.1 \\
\hline
\end{tabular}

\section{Discussion}

It can be seen from Table 1 that when the cold water temperature is $15^{\circ} \mathrm{C}$, the initial temperature of the water tank is $35^{\circ} \mathrm{C}$, and under the same heat collecting area, the annual collector efficiency of the flat-plate collector is $47.1 \%$, which is higher than that of the evacuated tube collector $4.2 \%$. The difference of the monthly average heat efficiency of the two kinds of heat collecting forms is shown in Fig. 4. It can be seen that the difference between spring and summer is large, and the difference between autumn and winter is small, especially in January, only $1.3 \%$. In combination with the outdoor average temperature of Table 2, it can be seen that the temperature is the lowest in January and the temperature is a little higher in February, and then is December, meanwhile the difference of the monthly average heat efficiency of both in January, February and December was relatively small. It shows that the outdoor temperature has great influence on the flat-plate solar collector, the lower the temperature is, the lower the heat collecting efficiency is. In September and October, the temperature is not low, and the heat collecting efficiency of both is also different. The main reason is that the temperature in the evening of September and October is low, which leads to the greater loss of heat. 


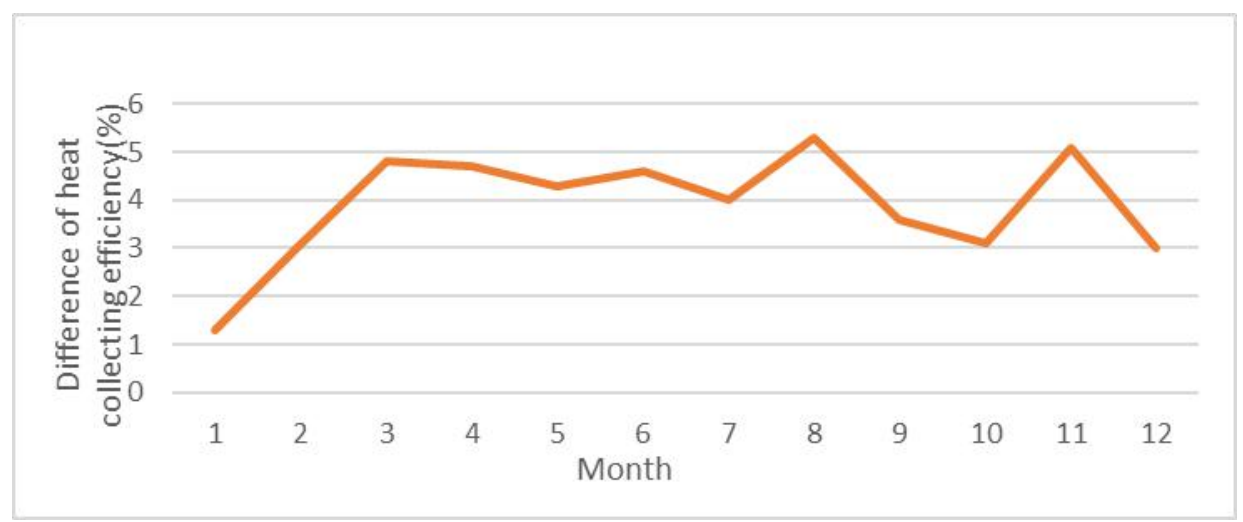

Fig. 4 the difference between the flat-plate collector and the evacuated tube collector

Table 2 Average temperature in Simulation month

\begin{tabular}{lllllllllllll}
\hline Month & Jan. & Feb. & Mar. & Apr. & May & Jun. & Jul. & Aug. & Sept. & Oct. & Nov. & Dec. \\
\hline $\begin{array}{l}\text { Temperature } \\
\left({ }^{\circ} \mathrm{C}\right)\end{array}$ & -2.4 & -1.6 & 6.8 & 14.4 & 20.7 & 24.2 & 26.1 & 25.5 & 20.7 & 14.3 & 5.3 & -0.6 \\
\hline
\end{tabular}

In the actual operation of the system, due to poor insulation performance of the flat-plate collector system, even if the daytime heat collecting is about the same, but at night due to low environmental temperature, heat loss in the system is more serious. Although the flat-plate collector efficiency is high, but in the course of the actual operation, the actual income of the user is not very good.

In addition, although the operation effect of the evacuated tube heat collector is better, pipe burst often appears because of the overpressure and overtemperature. A pipe burst, the whole system will be stopped due to the leakage of water, which brings great inconvenience to the operation and maintenance of the system. However, the phenomenon of tube explosion is rarely seen in the independent evacuated tube solar collector, indicating that the collective system also needs to be improved.

\section{Conclusion}

In view of the increasingly intense energy situation and the increasing impact of traditional energy on the environment, the utilization of solar water has developed rapidly in China. Due to the fact that the number of solar collectors installed on the roof of multi-storey and high-rise buildings is less and less, the application of collective solar water system in China has an expanding trend. More than $85 \%$ of China's heat collecting system adopts evacuated tube type, while in Europe and America, more than $90 \%$ of the flat-plate collector is used. In this paper, the advantages and disadvantages of two kinds of heat collector are analyzed from the evacuated tube solar collector and the flat-plate solar collector, and then the TRNSYS software is used to simulate and analyze the collecting efficiency of the two kinds of collectors. When the cold water temperature, the initial temperature of the water tank and the heat collecting area are the same, the conclusions are as follows:

(1) The total average heat collecting efficiency of the flat-plate collector is $47.1 \%$, which is $4.2 \%$ higher than that of the evacuated tube collector.

(2) Monthly comparison shows that the difference of heat efficiency between the two in August is the largest, which is $5.3 \%$, and the difference is the smallest in December, which is $1.3 \%$.

(3) Outdoor temperature has great influence on the collecting efficiency of flat-plate solar collector. The lower the ambient temperature is, the lower the collector efficiency is. The evacuated tube collector has better thermal insulation performance and less environmental impact. 


\section{Acknowledgments}

This work was supported by Tianjin Municipal Science and Technology Commission (Contract No.14ZCZDGGX00795) and Sina-Singapore Tianjin Eco-city Administrative Committee. The authors are thankful to anonymous reviewers for their valuable comments and feedback.

\section{References}

[1] Sharma, N, Diaz G. Performance model of a novel evacuated-tube solar collector based on minichannels.SolEnergy2011; 85: 881-90.

[2] Tyagi V, Kaushik S, Tyagi S. Advancement in solar photovoltaic/thermal (PV/T) hybrid collector technology. Renew Sust EnergRev2012; 16: 1383-98.

[3] Budihardjo I, Morrison G L, Behnia M. Development of TRNSYS models for predicting the performance of water-in-glass evacuated tube solar water heaters in Australia[C] Anzses Conference Melbourne. 2003.

[4] Zishuai Sun, Hanzhong Tao, Jiandong Zhang, et al. Double-layer glass cover plate solar collector numerical simulation [J]. thermal power generation, 2016, 45 (11): 54-60.

[5] Ayompe L, Duffy A, McKeever M, Conlon M, McCormack S. Comparative field performance study of flat plate and heat pipe evacuated tube collectors(ETCs) for domestic water heating systems in a temperate climate. Energy 2011; 36:3370-8. 